\title{
Educação dos tempos modernos através da aprendizagem colaborativa: uma abordagem sobre EDUSCRUM
}

\author{
Denise G. de Souza ${ }^{1}$, Viviane S. Vergottini ${ }^{1}$, Denise S. D. Bernini ${ }^{1}$ \\ ${ }^{1}$ Faculdade Brasileira - MULTIVIX - VITÓRIA \\ 29.075-053 - Vitória, ES - Brazil \\ denisesegal2015@gmail.com, vivisvergottini@gmail.com, \\ denise.sdb@gmail.com
}

\begin{abstract}
This study aims to discuss the implementation of the technological resource EDUSCRUM as a means for teaching-learning in active methodologies. It will be approached concepts of active methodologies, use of TDICs in education, and finally a case report will be presented with the application of EDUSCRUM, based on the SCRUM methodology, the Trello tool was used. After developing the project, it can be verified that the tool, together with the methodology, can offer a valuable resource in the teachinglearning process with active methodologies.
\end{abstract}

Resumo. Este estudo tem como objetivo discutir a implementação do recurso tecnológico EDUSCRUM como meio para ensino-aprendizagem em metodologias ativas. Serão abordados conceitos de metodologias ativas, uso das TDICs na educação, e por fim será apresentado um relato de caso com a aplicação do EDUSCRUM, baseado na metodologia SCRUM, foi utilizada a ferramenta Trello. Após desenvolvimento do projeto, pode-se verificar que a ferramenta aliada à metodologia, pode oferecer valoroso recurso no processo de ensino-aprendizagem com metodologias ativas.

\section{Introdução}

Este artigo busca desconstruir a visão tradicional sobre a educação, onde o professor é o detentor do conhecimento e o aluno um mero receptor de informações e conteúdos. Será abordada a metodologia ativa em que o aluno participa ativamente da construção do seu conhecimento, desenvolvendo suas habilidades e se tornando assim um cidadão mais completo e coerente para viver no século XXI,

Atualmente o aluno está a cada dia mais perdendo a motivação de estar em sala de aula recebendo conteúdos que muitas vezes não tem significado real para sua compreensão, além de que as escolas e os professores devem perceber que o mundo está evoluindo tecnologicamente e necessitando de um modelo de profissionais mais proativos, criativos, dinâmicos e questionadores.

A aprendizagem colaborativa é uma das alternativas que podem trazer de volta a motivação para o estudo, e assim a ferramenta Scrum, que normalmente é usada para desenvolver apenas projetos de software e hoje já está expandindo para um novo mercado que é a educação, e denominada EduScrum. Que funciona como uma nova forma de desenvolver o ensino aprendizagem mais coerente e atual. 
VII Congresso Brasileiro de Informática na Educação (CBIE 2018)

Anais do XXIX Simpósio Brasileiro de Informática na Educação (SBIE 2018)

O EduScrum é baseado em um ensino aprendizagem onde os alunos aprendem a resolver problemas complexos se adaptando a resolução de forma integrada com os colegas, produtiva e criativa. Sendo assim uma forma de contribuir para evoluir a metodologia das escolas e passar a educação tradicional para uma educação inovadora, desafiadora e com a necessidade e a cara dos alunos nos tempos modernos.

\section{A Educação em Tempos Atuais}

O Brasil atualmente vive em total desigualdade social e com isso implica nas condições ideais para se desenvolver um trabalho significativo na educação igualitária e de boa qualidade para todos os cidadãos. As Leis de Diretrizes e bases da educação nacional (LDB) Lei 9.394/1996, são pouco conhecidas e difundidas, poderiam ser melhores definidas e cumpridas pela gestão das escolas, professores, pais, alunos e comunidade, pois na maioria das vezes são desconhecidas.

Conforme o Art. 2o da LDB, TÍTULO II - Dos Princípios e Fins da Educação Nacional, a educação é dever da família e do Estado, inspirada nos princípios de liberdade e nos ideais de solidariedade humana e tem por finalidade o pleno desenvolvimento do educando, seu preparo para o exercício da cidadania e sua qualificação para o trabalho.

Ainda com base no que diz a LDB é importante saber o dever que todos têm para melhorar e dar maior sentido ao sistema de ensino nacional. Pois de acordo com a lei em relato ao artigo 14, os sistemas de ensino definirão as normas da gestão democrática do ensino público na educação básica, de acordo com as suas peculiaridades e conforme os seguintes princípios: I - participação dos profissionais da educação na elaboração do projeto pedagógico da escola; II - participação das comunidades escolar e local em conselhos escolares ou equivalentes.

Além disso, o Plano Nacional de Educação (PNE), aprovada por lei em 2014 e vigorará por dez anos. É ele que determina novas diretrizes, metas e estratégias na política da educação para tentar suprir as lacunas das leis que falamos anteriormente. E nessa última aprovação que irá vigorar até 2024, é diferente dos anos anteriores, visto que irá ultrapassar governos e ela ainda está em vigor e atuante.

Na prática, a arte de educar enfrenta um desafio secular, pois a geração de alunos de hoje é bem mais dinâmica do que a geração de alunos de 1996, segundo Cortella (2016), num mundo de mudança veloz, estamos no século XXI, nascidos no século XX e usando métodos que vinham do século XIX.

A procura por novos caminhos e abordagens para área educacional, vem da necessidade de acompanhar as mudanças econômico sociais que o mundo vem sofrendo ao longo dos anos. O autor Gadotti (2000), monta um retrato dessa necessidade, descreve que nas últimas duas décadas do século XX assistiu-se a grandes mudanças tanto no campo socioeconômico e político quanto no da cultura, da ciência e da tecnologia. Ocorreram grandes movimentos sociais, como aqueles no leste europeu, no final dos anos 80, culminando com a queda do Muro de Berlim. Ainda não se tem ideia clara do que deverá representar, para todos nós, a globalização capitalista da economia, das comunicações e da cultura. As transformações tecnológicas tornaram possível o surgimento da era da informação. 
VII Congresso Brasileiro de Informática na Educação (CBIE 2018)

Anais do XXIX Simpósio Brasileiro de Informática na Educação (SBIE 2018)

Assim pode-se dizer que é preciso estudar novas abordagens educacionais que possibilitem a evolução do ensino aprendizagem trazendo dinamismo neste processo, um exemplo são as metodologias ativas. Através delas é possível trabalhar diferentes formas de estruturar uma aula mais dinâmica e didática para apresentar o conteúdo aos alunos. De acordo com Alencar e Borges (2014), Metodologias Ativas podem ser colocadas em sala de aula, como formas de desenvolver o processo do aprender que os professores utilizam na busca de conduzir a formação crítica de futuros profissionais nas mais diversas áreas. A utilização dessas metodologias pode favorecer a autonomia do educando, despertar a curiosidade, estimular tomadas de decisões individuais e coletivas, vindo das atividades de rotina do dia-dia e em contextos do estudante. Uma das Metodologias ativas utilizadas é a problematização, que tem como objetivo instigar o estudante mediante problemas, pois assim ele tem a possibilidade de examinar, refletir, posicionar-se de forma crítica.

A seguir, são destacadas algumas estratégias utilizadas em sala de aula que possibilitam o professor um trabalho com resultados significativos aos alunos. São eles: Aula expositiva dialogada, estudo de texto, portfólio, tempestade cerebral, mapa conceitual, estudo dirigido, Phillips 66, grupo de verbalização e observação, dramatização, seminário, estudo de caso, júri simulado, simpósio, painel, fórum, oficina, estudo do meio e ensino com pesquisa. Segundo Fonseca e Neto (2017), metodologias ativas tem um conceito amplo, que pode se referir a uma variedade de estratégias de ensino, como: aprendizagem baseada em problemas, problematização, aprendizagem baseada em projetos, aprendizagem por pares (ou peer instruction), design thinking, método do caso e sala de aula invertida, dentre outras.

\section{Aprendizagem Colaborativa}

Uma metodologia que pode ser destacada é a aprendizagem colaborativa, que é a importante forma de colocar o aluno como participante ativo de sua aprendizagem. Segundo Torres e Irala (2014) a aprendizagem cooperativa tem sido frequentemente defendida no meio acadêmico atual, pois se reconhece nessas metodologias o potencial de promover uma aprendizagem mais ativa por meio do estímulo: ao pensamento crítico; ao desenvolvimento de capacidades de interação, negociação de informações e resolução de problemas; ao desenvolvimento da capacidade de autorregulação do processo de ensino-aprendizagem. Essas formas de ensinar e aprender, segundo seus defensores, tornam os alunos mais responsáveis por sua aprendizagem, levando-os a assimilar conceitos e a construir conhecimentos de uma maneira mais autônoma.

E assim, pode ser observada a importância de comparar os grupos de aprendizagem atuais e antigos, onde o aluno deixa de ser passivo no seu processo de aprendizagem e passa a ter opinião e autonomia para desenvolver da melhor forma um trabalho em grupo onde aprende a colocar suas ideias e aceita a sugestão dos demais, construindo assim uma forma real e concreta sobre o conteúdo apresentado pelo professor.

É importante que o professor dê espaço para o aluno planejar, discutir e entender melhor o funcionamento e o papel de cada aluno no grupo. $\mathrm{Na}$ aprendizagem colaborativa, os professores incentivam a autonomia e observam o ritmo de estudos e aprendizagem, além de redirecionar a sua autoridade em sala de aula para o grupo, e 
VII Congresso Brasileiro de Informática na Educação (CBIE 2018)

Anais do XXIX Simpósio Brasileiro de Informática na Educação (SBIE 2018)

incentivar a independência positiva. Dessa forma as disciplinas e os conteúdos se tornam de fácil compreensão e podem ser trabalhados em conjunto.

Para Moran (2017) numa perspectiva transdisciplinar, várias disciplinas são envolvidas, possibilitando uma visão ampla do conhecimento sobre o objeto em estudo. A aprendizagem vai além das temáticas selecionadas inicialmente devido ao próprio interesse do aluno. Assim, pode ser trabalhado um projeto numa perspectiva inter, multi ou transdisciplinar, dependendo do quanto se quer ampliar o interesse pelo conhecimento e pelas informações a serem aprofundadas através da relação entre as disciplinas e da realização da pesquisa.

A aprendizagem vai além dos conteúdos programados pelos professores, parte do interesse do aluno ampliar e aprofundar o conhecimento através de pesquisas, inclusive mesclando a relação entre as disciplinas. De acordo com Borges e Moraes (2013), a atuação do profissional em áreas distintas exigirá dele a capacidade de buscar por conta própria o conhecimento necessário, de autorregular o seu processo de aprendizagem e de trabalhar de forma colaborativa.

E para que o real significado da aprendizagem colaborativa tenha sentido é preciso ter como base os quatro pilares da educação realizados pelo autor e organizador do relatório para UNESCO, Jacques Delors, onde escreve Siqueira (2010) que a prática pedagógica deve preocupar-se em desenvolver quatro aprendizagens fundamentais, que serão para cada indivíduo os pilares do conhecimento: aprender a conhecer indica o interesse, a abertura para o conhecimento, que verdadeiramente liberta da ignorância; aprender a fazer mostra a coragem de executar, de correr riscos, de errar mesmo na busca de acertar; aprender a conviver traz o desafio da convivência que apresenta o respeito a todos e o exercício de fraternidade como caminho do entendimento; e, finalmente, aprender a ser, que, talvez, seja o mais importante por explicitar o papel do cidadão e o objetivo de viver.

O trabalho pedagógico de acordo com Bernini (2007) pode proporcionar atividades que podem ser chamadas de multimídia, situação em que o aluno tem contato com o conteúdo por variados recursos de comunicação. Mas cabe aqui apontar que a consciência de que alguns conhecimentos prévios são necessários e necessitam que o professor adquira novas habilidades e competências, tais como: noções técnicas do funcionamento de tais equipamentos para identificar as limitações e opções oferecidas por eles; programar adequadamente o uso dos recursos, impedindo que o método de trabalho seja alterado ou simplesmente ditado pelo recurso escolhido; criar um ambiente de aprendizagem colaborativa, motivador e rico em informações, possibilitando assim o desenvolvimento de um cidadão crítico, consciente e colaborador do processo.

É preciso pensar sobre como será e qual será o papel dos profissionais que estão sendo formados atualmente. Afinal será um grande desafio pois muitas vezes deve-se trabalhar em áreas distintas a sua formação. E para se tornar um sujeito inovador, capaz de transgredir em seu trabalho, deve-se ser criativo, tendo capacidade de socializar e abrir possibilidade para novas experiências.

Além disso, é preciso que os professores estejam atualizados e dispostos a experimentar ferramentas tecnológicas atuais, métodos e processos inovadores de 
VII Congresso Brasileiro de Informática na Educação (CBIE 2018)

Anais do XXIX Simpósio Brasileiro de Informática na Educação (SBIE 2018)

ensino-aprendizagem tornando a sala de aula um espaço de trocas e as aulas e conteúdos motivacionais aos alunos.

Segundo Bernini (2007), colocar à disposição do aluno variados recursos de comunicação, em que, este utiliza-se de múltiplos meios de acesso às informações, torna o processo ensino aprendizagem mais que uma simples aula e utilizando recursos disponíveis na Internet podemos proporcionar uma aprendizagem interativa $\mathrm{e}$ colaborativa, momento quando o aluno faz a opção do meio desejado na construção do seu conhecimento, tornando-se um participante ativo do processo de construção do conhecimento.

\section{Scrum}

A ferramenta que normalmente é conhecida no campo da tecnologia da informação para construção de projetos de software se define segundo o seu cocriador Sutherland (2016) uma forma de trabalhar em equipe. E nomeou de Scrum que faz referência a uma jogada do rugby onde todos do time se unem para avançar com a bola pelo campo e realizar uma jogada alinhada, com clareza dos objetivos, cuidados e união por um propósito.

As atividades com projetos se baseiam em trabalhar com equipe, de forma que tudo é organizado e eficiente para obtenção bons resultados aos projetos dos clientes. $\mathrm{O}$ que permite que todos tenham parte no processo e no desenvolvimento das atividades. $\mathrm{E}$ além disso, explicam Schwaber e Sutherland (2014), que o Scrum desenvolve um trabalho com times, onde há eventos a serem seguidos, responsabilidades, papéis prédefinidos e regras para todos. E cada membro do time tem seu trabalho para desenvolver e unir aos demais para o sucesso de todos e do projeto.

Essa forma de trabalho colaborativo exige que se tenha uma estrutura de pessoas responsáveis por cada parte ou etapa do projeto, afinal uma equipe trabalha junto em ideias, mas cada um tem a sua designação específica para o desenvolvimento do trabalho e que tenha coerência, além de etapas definidas como início, meio e fim. Por isso Bissi (2007) afirma que para iniciar o processo de trabalho com Scrum, inicialmente deve ser definida a equipe e a função de cada membro que vai fazer parte do projeto. No caso, essa equipe deve contar com 6 até 9 pessoas e se houver mais componentes deve-se formar outro grupo e dividir as tarefas para que cada equipe possa focar em um eixo que vá trabalhar com eficiência e entregar um trabalho de qualidade, onde todos tenham domínio do que desenvolvido.

Para além de projetos de tecnologia é interessante observar os meios em que se pode aplicar essa forma ágil de solução de problemas, como esclarece Bissi (2007) o Scrum pode ser aplicado em diferentes projetos, seja ele grande ou pequeno, mas que possa ser observado a evolução do processo, adaptando sempre que necessárias situações que são vistas necessidades de mudança, mas que fazem parte para melhorar os resultados.

\section{EduScrum}

A educação do século XXI e novas metodologias através de projetos como parte do ensino aprendizagem, promove a integração dos conteúdos e disciplinas tradicionalmente divididas e limitadas. A tecnologia avança de forma muito rápida nos 
VII Congresso Brasileiro de Informática na Educação (CBIE 2018)

Anais do XXIX Simpósio Brasileiro de Informática na Educação (SBIE 2018)

últimos tempos, com isso é importante que a evolução da educação caminhe em conjunto, possibilitando novas tendências de ensinar e aprender. Segundo Delhij, Solingen e Wijnands (2016) o EduScrum se baseia em um processo de transparência, onde pode ser tudo adaptado à realidade dos alunos e tornar as aulas uma experiência $\mathrm{e}$ estrutura de trabalho em equipe de forma autônoma.

Os alunos na Holanda, têm a oportunidade de participar atualmente em uma escola que proporciona o sistema de aulas com o eduScrum, visando que os alunos participem de uma tendência que chama atenção aos estudos de forma interessante, integradora e os prepara para o futuro de maneira significativa e real para os dias de hoje.

O mundo está em constante mudança, ainda mais nos últimos tempos, e é necessário que os professores mudem sua forma de pensar e possibilitar aos alunos demonstrarem a sua capacidade de pensar de forma crítica, inovar, aprender de maneira independentemente, colaborar e liderar grupos e projetos.

O eduScrum exige a participação ativa para construção do seu saber através de uma aprendizagem colaborativa por projetos. O aluno desenvolve o seu trabalho e conhecimento de acordo com sua participação expondo sua opinião, ouvindo a ideia dos colegas e contribuindo de forma questionadora, crítica, mas companheira, para os resultados serem atingidos em grupo e não individualmente.

$\mathrm{Na}$ forma de desenvolver o eduScrum deve-se ressaltar que cada participante tem o seu papel e deve seguir o formato inicial para que haja concordância e organização de trabalho. Segundo Borges, Nakle e Schimitt (2014) o professor, chamado de Scrum Master, é quem inicialmente conversa com os alunos sobre os projetos a serem trabalhados, acompanha o desenvolvimento do projeto, observa e auxilia no que for preciso para ajudar o grupo através de recursos, sanar alguma dúvida sobre o assunto ou inclusive se for necessário gerenciar conflitos que o grupo esteja sendo impossibilitado de evoluir no projeto. Já os alunos devem se organizar em pequenas equipes de no máximo 4 pessoas. Esse time deve eleger um líder e em cada ciclo de entrega de atividades, sempre um aluno diferente como representante. E a troca de aluno representante do time é importante para que todos exerçam o papel e a habilidade na liderança ou na frente de um time e tenham a oportunidade de aprender as responsabilidades que esse papel exerce. O papel do aluno representante é supervisionar as atividades que estão em andamento, além de ser o único canal direto com o professor, chamado de Scrum Master, para passar as dificuldades e necessidades do grupo durante a entrega das atividades (Sprints) durante o desenvolvimento do projeto.

A equipe se reúne para estabelecer e executar as cerimônias previstas pelo EduScrum, elaborar o escopo inicial das atividades do projeto, chamado de backlog. Em seguida, prepara o plano de desenvolvimento, chamado planning, que vai definir mais minuciosamente o que deve ser feito para entregar de forma concreta as atividades do planning, o grau de dificuldade para entrega de cada ítem também será votado no grupo, além de definir o conceito de pronto para que os alunos possam realmente ter certeza que o que estará pronto passou por esse acordo entre todos. A partir disso, os alunos se encontram diariamente e fazem uma reunião rápida, em pé, para dizer o que cada um fez no dia anterior, o que vai fazer no dia e se teve qualquer dificuldade. 
VII Congresso Brasileiro de Informática na Educação (CBIE 2018)

Anais do XXIX Simpósio Brasileiro de Informática na Educação (SBIE 2018)

A cada semana as equipes devem entregar por completo um planning, chamado de Sprints, e estabelecer o próximo para o desenvolvimento do projeto.

O projeto será finalizado após a entrega de todas as Sprints e a avaliação do Scrum Master.

Para dominar essa forma de desenvolver os conteúdos em estrutura de projetos e em grupos, é um desafio que os alunos e os professores devem estudar e praticar, pois não é algo simples de executar de uma hora para outra e obter sucesso em primeiro momento.

É preciso que todos juntos tenham uma formação contínua sobre o assunto eduScrum, com pessoas que já tem uma certa prática e assim produzir os projetos inicialmente menores, com menos tempo de duração e entregas de curto prazo, assim a prática começa a ser desenvolvida e melhorada a cada novo interesse e projeto estabelecido pela turma e professores. Para estruturar e colocar o EduScrum em prática podem ser utilizadas diferentes ferramentas para estruturar o projeto. O site Agile Classrooms traz alguns recursos como: Alliance Canvas que pode auxiliar na montagem do trabalho das equipes. E além disso, pode ser feito uma estrutura com o aplicativo Trello e até mesmo em um simples quadro branco onde os alunos podem dispor de post its para estruturar e organizar todo trabalho e projeto que almejam entregar de forma ágil e com qualidade, onde todos os participantes sejam ativos e tenham de fato aprendido o conteúdo necessário.

\section{Estudo de Caso}

O estudo foi aplicado com um grupo de alunos da pós-graduação, no desenvolvimento de uma atividade para uma das disciplinas. O objetivo do projeto era fundamentar o conhecimento em EduScrum criando um artigo acadêmico que abordasse o tema.

Inicialmente, a ideia era responder a seguinte pergunta: Como podem ser criados projetos, dentro do ambiente pedagógico, capazes de serem estruturados de forma ágil e funcional.

Para acompanhamento do projeto foi definida a utilização da ferramenta on-line Trello, que possibilitou o acompanhamento do projeto remotamente, bem como a realização das reuniões de forma remota. Também fora definido que o projeto seria entregue em 30 dias com 4 Sprints de 5 dias. 
VII Congresso Brasileiro de Informática na Educação (CBIE 2018)

Anais do XXIX Simpósio Brasileiro de Informática na Educação (SBIE 2018)

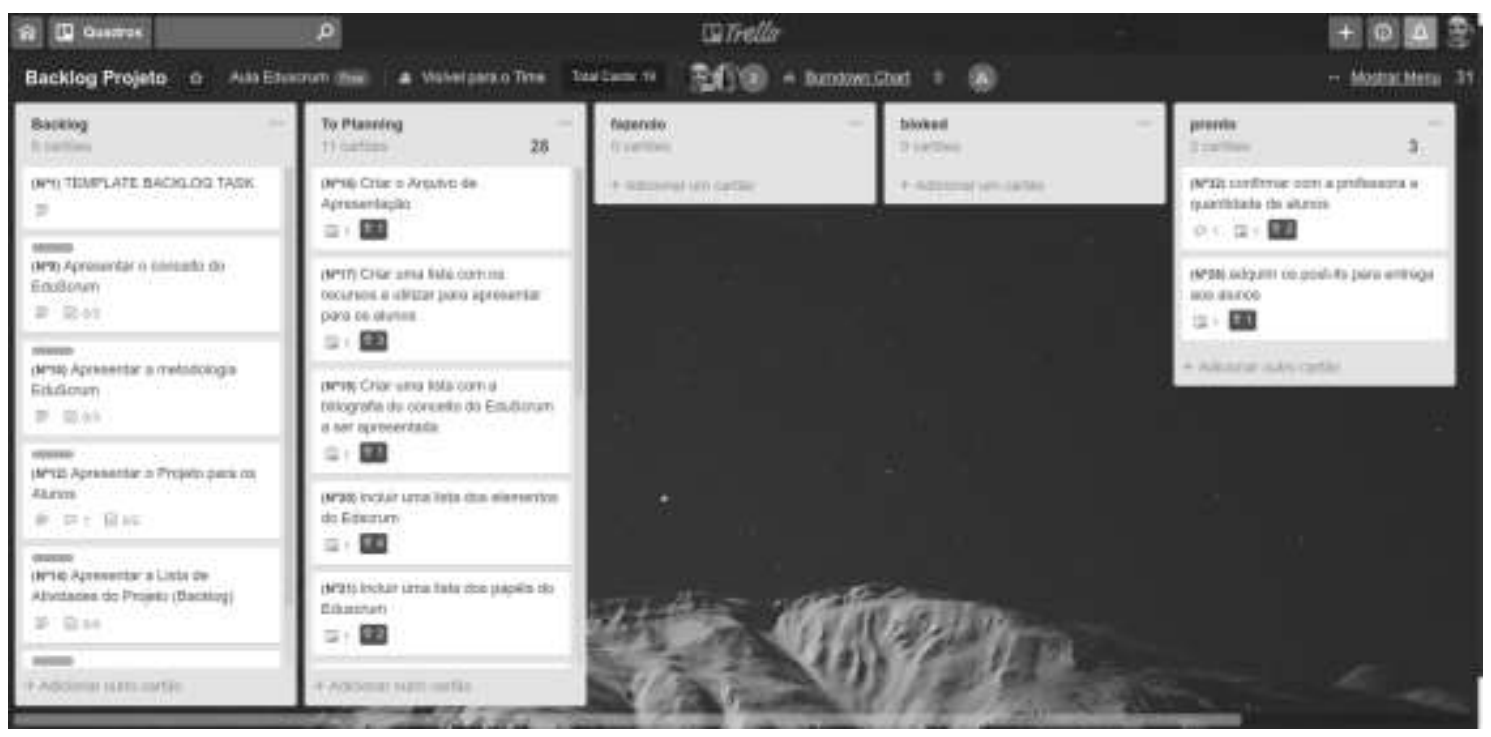

Figura 1 - Exemplo do Trello com o Backlog e o Planning de uma Sprint

Em seguida, foi definido o conceito de pronto e o Backlog, o primeiro consistia em um documento validado por todos os participantes que definia que uma atividade somente seria considerada pronta quando todos os envolvidos aprovassem a atividade. $\mathrm{O}$ segundo consistia em uma lista com todos os marcos a serem conquistados durante o projeto. Para estes marcos ficaram definidos que seria feito um levantamento dos principais conceitos de metodologias ativas, seria apresentado o conceito base do Scrum, método que é a referência a Metodologia do objeto de estudo deste artigo e por fim apresentado o conceito do EduScrum.

Adiante fora definido o Planning da primeira Sprint e em seguida fora realizada a abertura das atividades para aquela semana. Neste planejamento, foram avaliadas as atividades que seriam realizadas na primeira semana todas elas culminavam em alguma entrega, de acordo com o grau de dificuldade gerado. Para o grau de dificuldade foram definidos pontos de 1 a 5, aonde 1 uma tarefa capaz de ser executada em menos de uma hora, e 5 representava uma tarefa capaz de ser executada em até 5 horas. Para a primeira semana fora definido que haveria no máximo 25 pontos que seriam divididos entre os participantes do grupo.

A partir de então os alunos do grupo se reuniam todos os dias, remotamente para repassar o acompanhamento da Sprint, cada um apresentava o que havia feito no dia anterior, o que estaria disposto a realizar naquele dia e quais as dificuldades ele estaria enfrentando para realizar a atividade.

O professor no papel de ScrumMaster(SM) era responsável por ouvir os pontos de dificuldade e apontar formas de contornar ou como solucionar os problemas apresentados, vale a ressalva de que era permitido aos colegas do projeto propor formas de contorno ou soluções para os problemas os quais o SM validaria como solução adotada.

Ao final da primeira Sprint os alunos apresentaram as atividades entregues e realizaram um alinhamento de retrospectiva sobre a semana, levantando os pontos positivos e negativos percebidos durante o processo. Ao final realizaram um novo 
VII Congresso Brasileiro de Informática na Educação (CBIE 2018)

Anais do XXIX Simpósio Brasileiro de Informática na Educação (SBIE 2018)

planning para definir as atividades da segunda semana e iniciaram a nova Sprint. Este processo se repetiu pelas semanas seguintes até a finalização do projeto.

Através da pesquisa foi observado que colocar em prática para estruturar o nosso artigo pode ser útil na docência do ensino superior e gestão educacional.

A experiência da utilização do EduScrum para desenvolver, organizar, trabalhar em equipe mesmo à distância, foi eficiente na estruturação do projeto, tornando mais ágil, completo em menor tempo e principalmente desenvolvido em conjunto, onde o conhecimento e o trabalho foram totalmente compartilhados.

Foi observado que o EduScrum pode ser muito útil para desenvolvimento de projetos diversos, do mais simples ao mais complexo e inclusive para todas as idades e ideias criativas de grupos que tenham o mesmo objetivo ou interesse de algum assunto em comum.

\section{Conclusão}

Tendo em vista os aspectos observados e pesquisados, a importância que existe sobre a necessidade de mudança no campo da educação para formação de profissionais e cidadãos mais responsáveis, questionadores, sociáveis e coerentes em uma sociedade competitiva e que cobra resultados significativos.

O estudo possibilitou a vivência desde a idealização do projeto, seu desenvolvimento e finalização, utilizando a metodologia EduScrum apoiada na ferramenta Trello.

Assim foi possível confirmar que através de novas metodologias de ensino aprendizagem os alunos e professores do século XXI podem trabalhar com mais entusiasmo e segurança sobre os conteúdos de forma mais real e prática.

É preciso que os professores e alunos conversem entre si e trabalhem juntos para uma sociedade mais digna. Não basta mais a busca por conhecimento em bibliotecas, hoje o conhecimento está praticamente na palma da mão da grande maioria nas escolas e na sociedade em geral. Inovar é mudar o pensamento tradicional, sair da zona de conforto e manter-se atualizado em ferramentas positivas que auxiliam para um sucesso coletivo.

A tecnologia deve ser bem aproveitada, vivenciada com responsabilidade por pais, professores e alunos, assim juntos usufruir de algo importante para evolução sadia de todos.

\section{Referencias}

BERNINI, Denise S. D.. Formação de professores com e para o uso das Tecnologias da Informação e Comunicação. In: XXX Congresso da SBC - WIE ? XVI Workshop Sobre Informática na Escola, 2010, Belo Horizonte - MG. Anais do XXX CSBC 2010. Disponível em: < file://C:/Users/Admin/Downloads/2026-3207-1-PB.pdf > acesso em 29/03/2018. 
VII Congresso Brasileiro de Informática na Educação (CBIE 2018)

Anais do XXIX Simpósio Brasileiro de Informática na Educação (SBIE 2018)

BISSI, Wilson. Scrum, Metodologia de Desenvolvimento Ágil. CESUMAR, Maringá, 2007.

BORGES, K.; MORAES M. A Formação do Sujeito Inovador Apoiada no Uso de Projetos de Aprendizagem, Metodologias Ágeis e Ferramentas Colaborativas. IFRS, Rio Grande do Sul, 2013.

BORGES, K.; SCHMITT, M.; NAKLE, S. EDUSCRUM, Projetos de Aprendizagem Colaborativa Baseados em Scrum, IFRS, Rio Grande do Sul, 2014.

BRASIL, Ministério da Educação e Cultura, Plano Nacional de Educação - Perguntas Frequentes. Disponível em $<\mathrm{http}$ ://pne.mec.gov.br/perguntas-frequentes $>$, acesso em $30 / 11 / 2017$.

BRASIL, Senado Federal, Lei de Diretrizes e Bases da Educação. Disponível em $<$ http://www2.senado.leg.br/bdsf/bitstream/handle/id/529732/lei_de_diretrizes_e_bas es_1ed.pdf>, acesso em: 30/11/2017.

CORTELLA, Mário Sérgio. Educação escola e docência. Cortez Editora 2016.

EDU Scrum - Cooperação que dá asas, disponível em: <http://eduscrum.nl/>, acesso em $30 / 11 / 2017$.

FONSECA, M.; MATTAR NETO, J. Metodologias ativas aplicadas à educação a distância: revisão de literatura. Revista EDaPECI, São Cristóvão, SE, 2017.

GADOTTI, Moacir. Perspectivas Atuais da Educação. Disponível em: $<$ http://dx.doi.org/10.1590/S0102-88392000000200002>, acesso em 30/11/2017.

GARCIA, L.; DIRENE, A. Metodologia para implementação de estratégias colaborativas mediadas por ferramentas de interação síncrona. Tecnologias Sociedade e Conhecimento. UNICAMP, 2013.

$\begin{array}{llll}\text { GUIA } & \text { DO } & \text { SCRUM. }\end{array}$ $<$ https://www.scrumguides.org/docs/scrumguide/v1/Scrum-Guide-PortugueseBR.pdf $>$, acessado em: 30/11/2017

SIQUEIRA, J.; MIRANDA, D. Os Pilares de Jacques Delors. UNIASSELVI, 2008.

SUTHERLAND, Jeff. Scrum: a arte de fazer o dobro do trabalho na metade do tempo. Leya, São Paulo, 2012.

TORRES, P.; ALCANTARA, P.; IRALA E. Grupos de Consenso: Uma proposta de aprendizagem colaborativa para o processo de ensino-aprendizagem. Revista Diálogo Educacional, Curitiba, 2014.

TORRES, P.; IRALA E. Aprendizagem Colaborativa: Teoria e Prática. Disponível em: $30 / 11 / 2017$. 